\title{
Manchester Arena bombing: lessons learnt from a mass casualty incident
}

\author{
Ross J Craigie, ${ }^{1}$ P J Farrelly, ${ }^{1}$ R Santos, ${ }^{2}$ S R Smith, ${ }^{3}$ J S Pollard, ${ }^{4}$ D J Jones ${ }^{3}$
}

${ }^{1}$ Department of Paediatric Surgery, Royal Manchester Children's Hospital, Manchester, UK

${ }^{2}$ Department of Paediatric Radiology, Royal Manchester Children's Hospital, Manchester, UK

${ }^{3}$ Department of General

Surgery, Wythenshawe Hospital, Manchester, UK

${ }^{4}$ Department of General Surgery, Royal Bolton Hospital, Bolton, UK

\section{Correspondence to}

Ross J Craigie, Department of Paediatric Surgery, Royal Manchester Children's Hospital, Manchester M13 9WL, UK; ross. craigie@mft.nhs.uk

Received 16 February 2018 Revised 25 February 2018 Accepted 26 February 2018

\section{Check for updates}

To cite: Craigie RJ, Farrelly PJ, Santos R, et al. $J$ R Army Med Corps Epub ahead of print: [please include Day Month Year]. doi:10.1136/

jramc-2018-000930

\section{ABSTRACT}

On 22 May 2017 Salman Abedi detonated an improvised explosive device in the Manchester Arena resulting in 23 deaths (including the attacker). This was the deadliest terrorist attack on UK soil since the 2005 London bombings, but was only one of five mass casualty terrorist attacks in the UK in 2017. Preparation for mass casualty incidents (MCI) is obligatory, involving such methods as multiagency tabletop exercises, mock hospital exercises, as well as simulation and training for clinicians in managing the injuries that would be anticipated in such an event. Even in the best prepared units, such an incident will pose significant challenges due to the unpredictable nature of these events with respect to timing and number of casualties. Following an $\mathrm{MCl}$, local and national reviews are undertaken to assess the effectiveness of the response, but also to identify areas where lessons can be learnt and to disseminate these to allow inclusion in future planning. We present the experience following a mass casualty terrorist incident along with a number of lessons learnt from this event.

\section{INTRODUCTION}

Over the last three years, there has been an increase in the number of terrorist-related mass casualty incidents (MCIs) across Europe, and as of September 2017 the UK threat level from terrorism is severe (attack highly likely). ${ }^{1}$ After the Paris Attacks of November 2015, NHS England wrote to every NHS Trust requesting they provide a statement of readiness with respect to their preparedness for a major incident, and following this the Emergency Response Department of Public Health England facilitated simulated mass casualty exercises. In Greater Manchester this resulted in the rather prophetic Operation Socrates, which included a suicide bombing scenario resulting in a significant number of adult and paediatric casualties. This identified that Greater Manchester has a capacity to manage 300 casualties in a single incident with distribution of $\mathrm{P} 1$ patients to the four major trauma centres (MTCs) (three adult and one paediatric), P2 patients to the three trauma units and $\mathrm{P} 3$ patients to local emergency hospitals' (LEHs) walk-in centres and mass casualty treatment centres (Table 1).

In addition to strategic planning, the acquisition and maintenance of clinical (including surgical) skills need to be addressed. Unlike military surgeons who train in the planning and surgical management of mass battlefield casualties, those in civilian practice have little or no experience of managing such patients. Ballistic injuries account for only $0.53 \%$ of all recorded trauma injuries in the UK, ${ }^{2}$ and as such

\section{Key messages}

Acquisition and maintenance of definitive surgical trauma skills for civilian surgeons should be mandatory.

- Patient identification following a mass casualty incident is difficult, with paediatric casualties posing a significant challenge.

- Mass casualty incidents result in a significant knock-on effect for all acute medical and surgical services in the region.

- There will be a significant surgical workload following the event. Elective commitments will need to be cancelled to accommodate this.

- Injured children and their parents must be managed together in the same ward.

many UK surgeons will never manage such injuries during their career. With the introduction of MTCs and the subsequent centralisation of the multiply injured patient, skill retention for those working in LEHs is particularly challenging. Although the management of major trauma patients is included in the syllabus for both general and paediatric surgical trainees in the UK, it is acknowledged that advanced trauma skills are not readily gained in most UK surgical practice, and as such career-long development and maintenance of these skills are required. ${ }^{3}$ Skills can be developed using simulation and a number of courses address this need. The Definitive Surgical Trauma Skills course was adapted from its original military design and introduced in 2002 for civilian surgeons to gain experience in resuscitative and definitive surgical techniques. The Definitive Surgical Trauma Care course also teaches decision making and strategic thinking skills in the management of severely injured patients. For those in paediatric practice, there is a Surgical Skills for Paediatric Trauma course in Newcastle.

\section{THE ATTACK AND THE AFTERMATH}

As people were leaving the Manchester Arena following an Ariana Grande concert, a suicide bomber detonated an improvised explosive device resulting in 23 deaths (including the bomber). Of those killed, 20 died at the scene and three died shortly after arriving in hospital. The method and timing of presentation to hospital were variable; the first victims presented to an LEH having taken the bus, while the first patient to arrive at one of the MTCs was brought in a police car. Fifty-nine patients were transferred by the ambulance service. In total, 160 patients attended hospital, 40 of 


\begin{tabular}{|c|c|c|c|c|c|c|}
\hline \multirow[b]{2}{*}{ P1 } & \multirow[b]{2}{*}{$\begin{array}{l}\text { Salford Royal Hospital } \\
20\end{array}$} & \multicolumn{4}{|l|}{ Over 12 years } & \multirow{2}{*}{$\begin{array}{l}\text { Under } 12 \text { years } \\
\text { Royal Manchester Children's } \\
\text { Hospital } \\
20\end{array}$} \\
\hline & & $\begin{array}{l}\text { Manchester Royal Infirmary } \\
20\end{array}$ & $\begin{array}{l}\text { Wythenshawe Hospital } \\
20\end{array}$ & & & \\
\hline P2 & $\begin{array}{l}\text { Oldham Hospital } \\
15\end{array}$ & $\begin{array}{l}\text { Stepping Hill Hospital } \\
15\end{array}$ & $\begin{array}{l}\text { Royal Albert Edward Infirmary } \\
\text { (Wigan) } \\
15\end{array}$ & & & $\begin{array}{l}\text { Royal Bolton Hospital } \\
10\end{array}$ \\
\hline P3 & $\begin{array}{l}\text { Tameside Hospital } \\
40\end{array}$ & $\begin{array}{l}\text { North Manchester General } \\
\text { Hospital } \\
30\end{array}$ & $\begin{array}{l}\text { Rochdale Urgent Care Centre } \\
10\end{array}$ & $\begin{array}{l}\text { Fairfield Hospital } \\
20\end{array}$ & $\begin{array}{l}\text { Royal Bolton } \\
\text { Hospital } \\
20\end{array}$ & $\begin{array}{l}\text { WIC/MIU and mass casualty } \\
\text { treatment centres }\end{array}$ \\
\hline & & & P3 Adults \& pae & & & \\
\hline
\end{tabular}

MIU, minor injuries unit; WIC, walk in centre.

whom were children. Eighty-seven, including 19 children, were admitted, 28 to critical care (22 adults and six children).

The subsequent surgical workload was significant with over 400 hours of operating in the weeks following the incident. One hospital used 139 hours of theatre time in the first 10 days. $^{4}$ Orthoplastic injuries constituted the vast majority of cases; indeed of the 14 children admitted to the Royal Manchester Children's Hospital (Table 2), all patients had a soft tissue injury.

Following the incident hot (immediate) and cold (delayed) debriefs were conducted at departmental, hospital and regional levels. In July 2017, the Mayor of Greater Manchester commissioned a non-statutory independent review, led by Lord Kerslake. We present some of the learning points.

\section{LESSONS LEARNT}

\section{Patient identification}

It is recognised that failure to correctly identify patients can result in a serious risk to patient safety. Patients brought to the emergency department following a major incident will arrive from the scene with identity information hung around their necks. On arrival, a major incident identity label containing a prewritten major incident casualty number is assigned.

Verification of patient identity following an MCI can be challenging. This is particularly notable for children who may become separated from their family members, tend not to carry forms of identification and often dress the same. It is recommended that

Table 2 Types of injuries in the children admitted to the Royal Manchester Children's Hospital $(n=14)$

\begin{tabular}{lc} 
& Patients (n) \\
\hline Traumatic brain injury & 3 \\
Spinal injury (cord or fracture) & 0 \\
Chest trauma & 6 \\
\hline Abdominal trauma & 2 \\
Vascular trauma & 1 \\
Pelvic trauma & 0 \\
Single open fracture & 3 \\
Multiple open fractures & 6 \\
Nerve injury & 5 \\
\hline Hand trauma & 2 \\
Soft tissue injury & 14 \\
\hline Burns & 2 \\
\hline Maxillofacial injury & 3 \\
\hline Ocular trauma & 4 \\
\hline Ear trauma & 4 \\
\hline
\end{tabular}

patients maintain their major incident number until their identity is confirmed beyond doubt.

\section{Trauma meetings}

Due to the patterns of injuries seen in patients following a bomb blast, multiple teams are involved in the care of individual patients. Coordination of care is vital and is best met by regular trauma meetings where all involved must attend. At the Royal Manchester Children's Hospital, twice-daily multidisciplinary teams were conducted and involved all surgical specialties, anaesthetics, critical care, pain management, microbiology, audiology, child and adolescent mental health services, the rehabilitation team, and the senior hospital management. Other major trauma patients in the hospital who were not involved in the MCI were also included in this meeting. The frequency of these meetings should not be reduced too soon.

\section{Major trauma consultant}

Each of the MTCs used the role of a major trauma consultant ${ }^{5}$ in the days and weeks following the MCI. The consultants can come from any relevant acute specialty but need to have experience of the holistic and ongoing management of major trauma patients. They lead and coordinate the care of beyond discharge to community care and rehabilitation.

\section{Support from medical teams}

The assistance of medical colleagues was essential and should not be underestimated. During the initial hours following the Arena attack, patients suitable for discharge were identified by medical teams, thus freeing up hospital beds. They also provided ongoing support to all patients allowing surgical teams to concentrate on operating. In the children's trauma service in Greater Manchester, the major trauma rehabilitation lead is a consultant paediatrician and indeed the tertiary surveys were performed by this consultant.

\section{Military surgeon advice and input}

The experience of managing ballistic injuries by military surgeons is unmatched by any surgeon working in civilian practice. Following the Arena bombing, advice was sought from military surgeons at the Royal Centre for Defence Medicine, Queen Elizabeth Hospital Birmingham. Site visits were conducted by a multidisciplinary military team who provided advice, support and assurance. During the debrief sessions, the involvement of military colleagues received extremely positive feedback. It is proposed that in the event of future incidents, the involvement of military teams will become a standard operating procedure 
arranged through NHS England with coordination of the visit managed locally.

\section{The surgeon commander}

A surgeon commander is a role adopted by a clinician with significant experience in the surgical management of trauma. This individual does not operate but supports teams in individual theatres to make appropriate decisions on surgical prioritisation and the use of damage control surgery. This role is entrenched in military practice, but is much less established in the civilian setting. Such a role has been identified as vital following the debriefs from the recent MCIs in the UK and Europe.

\section{Effect of MCl on LEHs}

It needs to be recognised that major incidents also have a significant knock-on effect to all hospitals within a region. Routine surgical and medical emergencies continue despite the MCI. Additionally, MTCs may divert to LEHs, resulting in an increase in attendances across all acute specialties, an increase in demand for beds and an increase in emergency theatre use.

Many tertiary acute medical and surgical services such as acute stroke, cardiac care and vascular surgery are colocated in hospitals designated as MTCs. In a large-scale MCI, transfers to tertiary care may not be possible due to the lack of ambulances and the demand on the tertiary centre, resulting in suboptimal care. The management of the region's routine emergency care in LEHs needs to be taken into account when planning for an MCI.

\section{Communication}

Communication during major incidents is key. During such events, hospital switchboards can be overwhelmed by both internal and external calls, and due to the construction of many modern hospitals mobile phone signal can be poor or non-existent. During the incident, many teams in all the hospitals that received patients used a WiFi-based communication system (WhatsApp, WhatsApp, USA) for both instant messaging and voice contact. This platform also had the benefit of being secure as a result of end-to-end encryption.

\section{Keeping families together}

Admission of children to hospital is associated with both child and parental anxiety even in the elective setting. This is magnified in an MCI where there is confusion, disorientation and potential separation of family members. Colocation of children (Royal Manchester Children's Hospital) and adult (MRI) services on the Central Manchester hospital site allowed injured parents and children to be managed in the same ward within the children's hospital. We recommend that in the event of future MCIs, families are managed in the same ward. Although this may be challenging for stand-alone children's hospitals, it must be addressed during subsequent mass casualty exercises.

It was also noted that parents did not want reconstructive surgery on the same day as their children and this should be taken into account when planning surgical intervention.

\section{Radiology}

The complex, and sometimes life-threatening, pattern of blast injuries requires a careful but quick radiological assessment of the different mechanisms seen, including shrapnel-related ones. A balance between the most effective radiological modality and its associated radiation burden is not always easy to achieve in MCI. During debrief sessions following the Arena blast, radiologists noted that reporting scans of a high volume of severely injured patients were hindered by interruptions from an overwhelming number of clinical teams seeking information to allow planning of surgical intervention. This led to queries as to the most appropriate way to document and convey findings to the clinical teams, which resulted in a proposed CT template report, the most used imaging modality, adjusted from the standards of practice and guidance for trauma radiology in severely injured patients (Figure 1). ${ }^{6}$

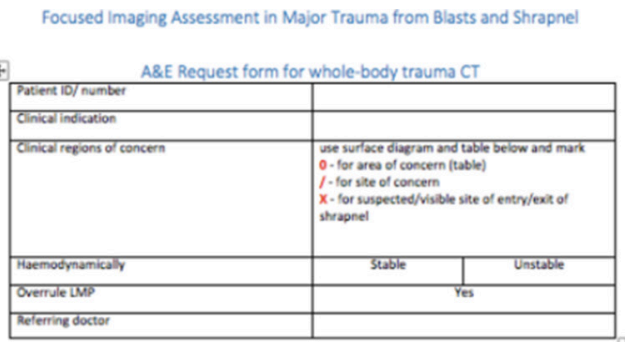

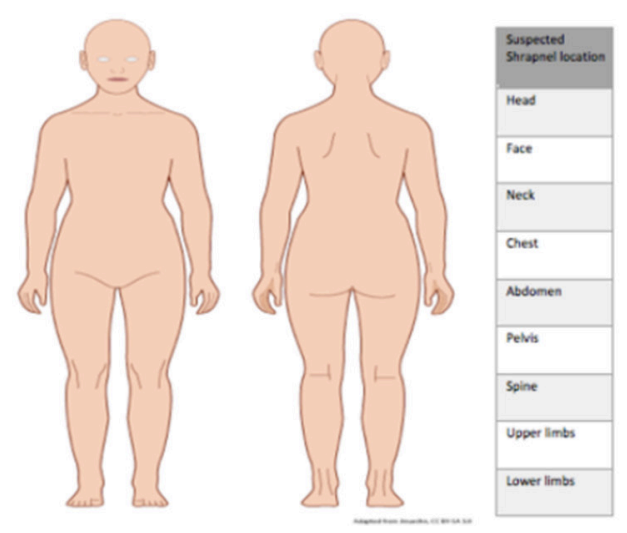

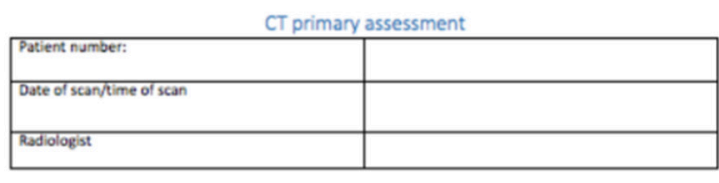

Purpose: To guide emergent management only. Formal detalled report will follow.

\begin{tabular}{|c|c|c|c|c|}
\hline \multicolumn{5}{|l|}{ Airway } \\
\hline IT placement & \multicolumn{2}{|l|}{$\mathrm{N} / \mathrm{A}$} & \begin{tabular}{|l|} 
Sotisfactory \\
\end{tabular} & Unsatisfactory \\
\hline Arway obstruction & \multicolumn{2}{|l|}{ Yes } & \multicolumn{2}{|l|}{ No } \\
\hline \multicolumn{5}{|l|}{ Breathing } \\
\hline \multicolumn{5}{|l|}{ Pneumothorax } \\
\hline \multicolumn{5}{|l|}{ Contusion } \\
\hline \multicolumn{5}{|l|}{ Laceration } \\
\hline \multicolumn{5}{|l|}{ Chest drain placement } \\
\hline \multicolumn{5}{|l|}{ Chrculation (Bleeding) } \\
\hline Thorack & \multicolumn{3}{|l|}{ Yes } & No \\
\hline Abdominal & \multicolumn{3}{|l|}{ Yes } & No \\
\hline Pelvic & \multicolumn{3}{|l|}{ Yes } & No \\
\hline Solt tissue & \multicolumn{3}{|l|}{ Yes } & No \\
\hline Upper limb & Yes & RT & UT & No \\
\hline Lower limb & Yes & RT & DT & No \\
\hline \multicolumn{5}{|l|}{ Disability(brain and spine) } \\
\hline Intractranial bleed/oedema & \multicolumn{3}{|l|}{ Yes } & No \\
\hline Mass effect/mid/ne shift & \multicolumn{3}{|l|}{ Yes } & No \\
\hline Major spinal injury & \multicolumn{3}{|l|}{ Yes } & No \\
\hline
\end{tabular}

Figure 1 Standardised CT reporting template. 
Use of the Swan bereavement model

In order to support the families of those individuals who were killed as a result of the bombing, the Swan bereavement model was implemented. All of the deceased were taken to a single mortuary and their relatives were directly supported by the bereavement team for the first 72 hours. Following this they were assigned a named bereavement nurse and had access to a 24/7 dedicated helpline.

\section{SUMMARY}

Unfortunately it is inevitable that further terrorist-related MCIs will occur in the UK. In addition to the acquisition and maintenance of definitive surgical skills, it is important for clinicians and healthcare providers to consider the processes by which MCIs are managed in order to prepare for such an event. Finally, it is essential to learn from the review of other incidents and incumbent on those who have been involved in such incidents to inform others of the lessons learnt.

Acknowledgements The authors wish to thank the Greater Manchester Academic Centre for Acute Care and Trauma (GM-aCAT) for providing data.

Contributors All the authors were involved in designing the concept of the paper and contributed to drafting the article. When the article was completed, all authors critically reviewed it. All authors (RJC, PJF, RS, SRS, JSP and DJJ) gave approval of the final version to be published.

Funding The authors have not declared a specific grant for this research from any funding agency in the public, commercial or not-for-profit sectors.

Competing interests None declared.

Patient consent Not required.

Provenance and peer review Not commissioned; internally peer reviewed.

(c) Article author(s) (or their employer(s) unless otherwise stated in the text of the article) 2018. All rights reserved. No commercial use is permitted unless otherwise expressly granted.

\section{REFERENCES}

1 Cabinet Office. National risk register of civil emergencies 2017 edition.

2 Davies MJ, Wells C, Squires PA, et al. Civilian firearm injury and death in England and Wales. Emerg Med J 2012;29:10-14.

3 The Intercollegiate Surgical Curriculum. Educating the surgeons of the future: general surgery. October 2013. Including Simulation (Updated 2015). https://www. iscp. ac.uk/curriculum/surgical/surgical_syllabus_list.aspx (last accessed 14 Jun 2017).

4 Smith SR, Craigie R, Pollard JS, et al. Trauma training: mandatory 'fire training' for general surgeons? RCS Bulletin 2017;99:312-5.

5 Royal College of Surgeons. Major trauma workforce sustainability. Outcomes of the RCS major trauma workgroup, 2016.

6 RCR. Standards of practice and guidance for trauma radiology in severely injured patients, 2015. 